\title{
Delivery and Receipt of a Self-Determination-Theory- Based Extracurricular Physical Activity Intervention: Exploring Theoretical Fidelity in Action 3:30
}

\author{
Simon J. Sebire, Mark J. Edwards, Kenneth R. Fox, Ben Davies, \\ Kathryn Banfield, Lesley Wood, and Russell Jago \\ University of Bristol
}

\begin{abstract}
The implementation, fidelity, and receipt of a self-determination-theory-based after-school physical activity intervention (Action 3:30) delivered by teaching assistants (TAs) was examined using a mixed-methods process evaluation. Physical activity motivation and need satisfaction were reported by 539 participants at baseline, the end of intervention, and 4-month follow-up. Pupil- and TA-reported autonomy-support and teaching efficacy were collected alongside interviews with 18 TAs and focus groups with 60 participants. Among intervention boys there were small increases in identified, introjected, and external motivation and no differences in need satisfaction. Among girls, intrinsic and identified motivation and autonomy and relatedness were lower in the intervention group. Qualitative evidence for fidelity was moderate, and boys reported greater need satisfaction than girls. TAs provided greater structure than involvement or autonomy-support and felt least efficacious when facing school-based challenges. The findings highlight the refinements needed to enhance theoretical fidelity and intervention effectiveness for boys and girls.
\end{abstract}

Keywords: intervention, children, evaluation

Physical activity declines steeply during the transition into adolescence (Nader, Bradley, Houts, McRitchie, \& O'Brien, 2008), and increasing the physical activity of school-age children would benefit their health (Janssen \& LeBlanc, 2010). A potential strategy to reduce the agerelated decline in activity is to ensure that children leave primary school with good physical literacy, confidence in their physical abilities, and positive motivations to be active. The benefits of incorporating physical activity interventions into school settings are well documented

C 2016 The Authors. Published by Human Kinetics, Inc. This is an Open Access article distributed under the terms of the Creative Commons Attribution License CC BY 4.0, which permits unrestricted noncommercial and commercial use, distribution, and reproduction in any medium, provided the original work is properly cited, the new use includes a link to the license, and any changes are indicated. See https://creativecommons.org/ licenses/by/4.0/. This license does not cover any third-party material which may appear with permission in the article.

Simon J. Sebire, Mark J. Edwards, Kenneth R. Fox, Ben Davies, Kathryn Banfield, Lesley Wood, and Russell Jago are with the Centre for Exercise, Nutrition \& Health Sciences, School for Policy Studies, University of Bristol, Bristol, UK. Address author correspondence to Simon J. Sebire at simon.sebire@ bristol.ac.uk.
(Wechsler, Devereaux, Davis, \& Collins, 2000). One way to build the capacity of primary schools to deliver physical activity is to train teaching assistants (TAs), who are staff in schools working alongside teachers in classrooms to support children's learning (Jago et al., 2013). In addition to identifying a sustainable source of intervention deliverers, the incorporation of psychological theory in intervention design is fundamental (Glanz \& Bishop, 2010) as solid theoretical foundations facilitate the selection of behavior change techniques and the avoidance of strategies that may undermine hypothesized mediators of change. Theories also provide a lens through which to evaluate intervention implementation and fidelity (Kok, 2014; Moore et al., 2014).

\section{The Action 3:30 Feasibility Trial}

We have reported the design (Jago et al., 2013), randomized controlled feasibility trial outcomes (Jago et al., 2014), and aspects of process evaluation (Jago et al., 2015) of an extracurricular intervention (Action 3:30) aimed at increasing the physical activity of children in Years 5 and 6 of UK primary school (i.e., 9-11 years of age). Action 3:30 was conducted in 20 schools (10 intervention, 10 control) in the greater Bristol (UK) area (Trial Registration No. ISRCTN58502739). The intervention provided two TAs from each intervention school with a 
5-day training program to develop the skills and resources needed to deliver an after-school physical activity club. TAs then delivered two 60-min after-school activity sessions per week for 20 weeks (i.e., 40 sessions). Control schools did not receive the intervention (i.e., TAs were not trained, and after-school Action 3:30 sessions were not provided). The trial analysis for evidence of promise suggested that after adjustment for baseline values, boys did 9 more minutes of moderate-to-vigorous physical activity per weekday than the control group at the end of the intervention. There was no evidence of an intervention effect for girls (Jago et al., 2014). The intervention was guided by self-determination theory (SDT; Deci \& Ryan, 2000; Ryan, Patrick, Deci, \& Williams, 2008), and the aim of this paper is to report a process evaluation of how well the SDT-based intervention elements were implemented and received.

\section{Motivation From the Self- Determination Theory Perspective}

SDT has been employed extensively to understand the motivation underpinning people's health behaviors $(\mathrm{Ng}$ et al., 2012)_in particular, people's physical activity motivation (Owen, Smith, Lubans, $\mathrm{Ng}$, \& Lonsdale, 2014; Teixeira, Carraca, Markland, Silva, \& Ryan, 2012). The theory has also been used to guide health behavior interventions (Fortier, Duda, Guerin, \& Teixeira, 2012). Within SDT, motivation is organized on a continuum of self-determination (Deci \& Ryan, 2000). The most self-determined form, intrinsic motivation, represents behavior performed for the inherent satisfaction it derives rather than any separable consequence (e.g., the enjoyment or pleasure of being active). Motivation driven by instrumental reasons is termed extrinsic and can be divided into autonomous and controlled types. Autonomous types of extrinsic motivation include actions driven by valued benefits such as spending time with friends or keeping fit (i.e., identified motivation) and where a behavior is aligned with a person's broader sense of self (i.e., integrated motivation). Controlled types of extrinsic motivation include motivation rooted in a desire to gain internal rewards such as self-approval or avoiding self-disapproval (i.e., introjected motivation) and external regulation in which gaining external rewards, complying with demands, or avoiding punishments (e.g., being active to please a teacher or to avoid being told off) drives behavior. Amotivation represents instances where a person has no intention or a lack of motivation to undertake a given behavior (e.g., physical activity). Children's autonomous motivation for physical activity is positively associated-whereas controlled types of motivation are generally found to be negatively or not associated-with their physical activity (Dishman, McIver, Dowda, Saunders, \& Pate, 2015; Owen et al., 2014; Sebire, Jago, Fox, Edwards, \& Thompson, 2013).

Evidence from physical education (PE) (Ntoumanis $\&$ Standage, 2009), sport (Amorose \& Anderson-Butcher,
2007), and physical activity (Sebire et al., 2013) domains supports the hypothesis that children's motivation will be autonomous rather than controlled to the degree that they experience the satisfaction of three psychological needs for autonomy (i.e., a feeling of volition), competence (i.e., possessing the relevant skills to act effectively), and relatedness (i.e., feeling socially connected, respected, and cared for) (Deci \& Ryan, 2000).

\section{Facilitation of Autonomous Motivation Through Autonomy- Supportive Teaching}

Of relevance to intervention developers is that within SDT, the motivating style of activity leaders, coaches, or teachers can provide support for or undermine the participants' need satisfaction (Ryan et al., 2008). An autonomysupportive teaching style involves nurturing individuals' interests and self-initiation, taking their perspective, being responsive to their preferences, offering choice, and providing positive feedback. Autonomy-supportive leaders will also show a personal interest in the pupils' lives and create learning environments underpinned by adequate structure, clear expectations, and guidelines (Mageau \& Vallerand, 2003; Reeve, Jang, Carrell, Jeon, \& Barch, 2004). In contrast, a controlling teaching style is characterized by pressure, coercion, the provision of controlling feedback, contingent praise, the use of controlling language, and a focus on ego-involvement (e.g., emphasizing performance over process) (Bartholomew, Ntoumanis, \& Thogersen-Ntoumani, 2009). Autonomysupportive versus controlling motivational styles are positively associated with children's and adolescents' need satisfaction in sport (Mouratidis, Lens, \& Vansteenkiste, 2010) and PE (Mouratidis, Vansteenkiste, Lens, \& Sideridis, 2008).

Social agents can be trained to use an autonomy-supportive teaching style (Aelterman, Vansteenkiste, Van den Berghe, De Meyer, \& Haerens, 2014; Tessier, Sarrazin, \& Ntoumanis, 2010). As such, SDT is being increasingly used to inform children's school-based physical activity interventions in PE lessons (Chatzisarantis \& Hagger, 2009; Lonsdale et al., 2013), non-PE curriculum lessons (Contento, Koch, Lee, \& Calabrese-Barton, 2010; Pardo, Bengoechea, Julian Clemente, \& Lanaspa, 2014), and after-school settings (Robbins et al., 2013; Wilson et al., 2011). Of the studies in the after-school period, the results of only one (a 17-week after-school physical activity program for low-income and minority adolescents) are published (Wilson et al., 2011). In this intervention, deliverers received training in creating an environment to target autonomous motivation and need satisfaction, and it was associated with 5 additional minutes of activity per day when the program was running; however, this was not maintained at follow-up (Wilson et al., 2011). The intervention group reported higher levels of enjoyment and choice during the intervention compared with controls. 
There are three main limitations to the existing SDT-informed school-based physical activity intervention research. First, the majority of this work has either made changes to the formal curriculum or trained regular teachers (e.g., PE or science teachers) to deliver the intervention, and there is little research concerning interventions in other school-based contexts (e.g., after-school programs). Second, there is no research with primaryschool-age children. As physical activity declines at the end of primary school (Nader et al., 2008) and younger children are likely to pose different challenges to the delivery of SDT-based interventions, it is important to deliver and evaluate interventions in this group. Third, the existing literature does little to extend our knowledge of how the theoretical components embedded within the interventions are delivered and received in practice. Although the Active by Choice Today (Wilson et al., 2009) and Choice Control and Change (Gray, Contento, $\&$ Koch, 2015) trials included process evaluation, theoretical/intervention fidelity was only quantified through observation. While this approach provides systematic and objective measures of fidelity, alternative person-centered qualitative approaches could provide further insight into the delivery and receipt of SDT-based components. Unpacking the experiences of intervention deliverers and participants would help identify where theoretical fidelity was good and where it broke down and where the intended messages might have been successful and where they were "lost in translation." Such insight can contribute much to the ongoing development of behavior change interventions (Moore et al., 2014).

\section{Self-Determination Theory in the Action 3:30 Intervention}

In Action 3:30, primary school TAs received training to deliver extracurricular physical activity sessions for children that aimed to support the children's psychological needs and build autonomous physical activity motivation (Jago et al., 2013). The training included a half-day session that covered SDT concepts, autonomy-supportive delivery, role-playing of autonomy-supportive teaching, and time to reflect and ask questions. The motivational concepts were shared with the individual who delivered the remainder of the training (a Local Authority employee experienced in training sports coaches) to ensure SDT principles were reinforced throughout. 15-150115As were provided with an intervention manual that contained information on motivation, practical teaching strategies, and advice on issues such as giving praise and rewards and dealing with disruptive behavior.

\section{The Present Study}

We have previously published part of the Action 3:30 process evaluation (Jago et al., 2015) that was restricted to analysis of data on trial recruitment, intervention attendance, participant perceptions of enjoyment, reasons for nonattendance, fidelity to session objectives, and school context, including competing after-school activities. Recent UK guidance on process evaluation of complex interventions supports the publication of multiple process evaluation papers to ensure sufficient coverage of the range of data and evidence collected (Moore et al., 2014). This paper uniquely reports data from the process evaluation of the theory-based components of the Action 3:30 intervention. Specifically, we sought to (a) examine preliminary quantitative evidence of promise and participants' and TAs' qualitative perceptions of the effectiveness of the Action 3:30 intervention on motivation and need satisfaction; (b) examine TAs' fidelity to the theoretical components of the intervention, their experiences of delivery, and participants' perceptions of their delivery style; and (c) identify improvements that could be made to the theoretical components of the intervention. All papers published from the Action 3:30 project can be found on the study website (http://www.bristol.ac.uk/sps/ research/researchprojectpages/action330/).

\section{Method}

School and participant sampling, recruitment, and allocation to trial arms has been described elsewhere (Jago et al., 2013). Repeated quantitative measures and qualitative interviews and focus groups were used to inform a mixed-methods process evaluation. The study received ethical approval from the University of Bristol's School for Policy Studies Research Ethics Committee. Written informed consent was obtained for all adult participants, and written parental consent was obtained for children.

\section{Quantitative Data}

All participants completed questionnaires assessing their physical activity motivation and psychological need satisfaction before randomization (baseline, Time 0), in the final weeks of the 20-week intervention (Time 1), and 4 months after the intervention ended (Time 2). During the intervention, four process evaluation visits (i.e., every 5 weeks, herein called PEV1 to PEV4) were made to all intervention schools in which participants reported their perceptions of TA autonomy-support and TAs reported their self-efficacy for physical activity teaching and their autonomy-support.

Motivation for Physical Activity. Participants reported their intrinsic, identified, introjected, and external physical activity motivation using a 12-item scale developed using items from the Behavioral Regulations in Exercise Questionnaire (Mullan, Markland, \& Ingledew, 1997) that were adapted to simplify the language and refer specifically to physical activity. Previous work provides evidence for the construct and concurrent validity of scores among primary-school-age children (Sebire et al., 2013). A 5-point Likert scale (i.e., ranging from 1 $=$ not true for me to $5=$ very true for me) was used, and responses were averaged within the four three-item 
subscales. Average internal consistency over the three measurement occasions was intrinsic $\alpha=.81$, identified $\alpha=.70$, introjected $\alpha=.61$, and external $\alpha=.70$.

Psychological Need Satisfaction. Participants' need satisfaction was assessed using three six-item scales that show construct and concurrent validity among primaryschool-age children (Sebire et al., 2013). The reliability of the competence and relatedness subscales were $\alpha=$ .73 and $\alpha=.84$, respectively. Following deletion of one reverse-coded item (i.e., "I have to force myself to be active") that reduced the reliability of the item set, the internal consistency of the autonomy scale was $\alpha=.75$.

Children's Perceptions of TA Autonomy-Support. Children completed six items on a 7-point scale (ranging from $1=$ strongly disagree to $7=$ strongly agree) rating their TA's autonomy-support (e.g., "I feel that my Action 3:30 teachers provide me with choices and options"). Items have been previously used in the PE context (Standage, Duda, \& Ntoumanis, 2006) and were modified for primary school children in this study (e.g., "My Action 3:30 teacher expresses confidence in my ability to do well" was changed to "My Action 3:30 teacher is confident in my ability to do well"). Because of variable attendance, the number of participants differed across each PEV time point (PEV1 $n=146, \operatorname{PEV} 2 n=117$, PEV3 $n=102$, PEV4 $n=110$ ). Sixty-five pupils provided data on all four occasions. The pattern of findings when all responses were analyzed was almost identical to that of those who provided complete data. As such, the former were reported. Over all assessments, the internal consistency was as follows: mean $\alpha=.89, S D=.02$, range $=$ .86 to .91 , intraclass correlation coefficient $($ ICC $)=.84$.

TA Self-Efficacy for Physical-Activity-Based Teaching. TAs completed an adapted version of the Physical Education Teachers' Physical Activity Self-Efficacy Scale (Martin \& Kulinna, 2003) at each of the four PEVs (PEV1 $n=19, \operatorname{PEV} 2 n=17, \operatorname{PEV} 3 n=17, \mathrm{PEV} 4 n=14$ ) to report their confidence of providing large amounts of physical activity (i.e., at least $50 \%$ of class time) when faced with Student, Space, Time, and Institutional challenges. References to PE were replaced with Action 3:30. Responses were given on a scale ranging from 0 (not confident at all) to 100 (very confident). Subscale means and internal consistency at each measurement point were calculated, with results as follows: Student subscale mean $\alpha=.98$, $S D=.01$, range $=.96$ to $.99, \mathrm{ICC}=.82$; Space subscale mean $\alpha=.94, S D=.01$, range $=.92$ to .95, ICC $=.53$; Time subscale mean $\alpha=.92, S D=.01$, range $=.91$ to .95 , ICC $=.82$; and Institution subscale mean $\alpha=.88$, $S D=.03$, range $=.84$ to $.93, \mathrm{ICC}=.77$.

TA Autonomy-Support, Involvement, and Structure. TAs completed 23 items assessing their autonomysupport (8 items tapping Choice, Relevance \& Respect, e.g., I let students make a lot of their own decisions regarding Action 3:30), involvement (8 items tapping Attunement \& Dependability, e.g., I know a lot about what goes on for these students), and structure (7 items tapping Contingency, Expectations \& Help/Support, e.g., I talk with students about my expectations for them). To reduce the burden, 23 items that best reflected teaching after-school physical activity (i.e., not referring to schoolwork and assignments) were drawn from the 41-item Teacher as Social Context Questionnaire (Belmont, Skinner, Wellborn, \& Connell, 1998). The stem of the questionnaire was adapted to focus TAs' responses on their Action 3:30 pupils. Mean scores were calculated for the three subscales at each PEV (PEV1 $n=19, \operatorname{PEV} 2 n=$ 17, PEV3 $n=17$, PEV4 $n=14$ ) with results as follows: Autonomy-Support mean $\alpha=.75, S D=.14$, range $=.59$ to .91 , ICC $=.94$; Involvement mean $\alpha=.80, S D=.06$, range $=.73$ to .88, ICC $=.95$; and Structure mean $\alpha=$ $.68, S D=.11 ;$ range $=.52$ to $.78 ; \mathrm{ICC}=.76$.

Covariates. Previous research suggests that children's body mass index (BMI) (Janssen \& LeBlanc, 2010) and socioeconomic position (Hanson \& Chen, 2007) are associated with their physical activity. Children's height and weight were measured as described previously (Jago et al., 2014), and age- and sex-specific BMI (BMI $z$ score) was calculated (Cole, Freeman, \& Preece, 1995). An individual index of multiple deprivation was estimated based on parent-reported home postcode, using the English Indices of Deprivation (http://data.gov.uk/dataset/ index-of-multiple-deprivation).

\section{Qualitative Data}

The qualitative process evaluation methods have been described elsewhere (Jago et al., 2015). For this paper, the qualitative data that refer to SDT were analyzed. Briefly, 18 (16 female) of the 20 TAs took part in a postintervention semistructured interview (mean duration $=$ $29.00, S D=9.91 \mathrm{~min}$ ). The topic guide covered a range of areas including session delivery, successes and difficulties, relationships with participants, perceived effects of the intervention, and effects on their knowledge/skills. Some questions (e.g., "What were your experiences of using the motivational techniques?") were specific to the SDT-focused delivery, and others were more general (e.g., "Were there any difficulties you experienced with the delivery of the sessions?") but provided opportunities for TAs to speak about factors that may have impacted theoretical fidelity. Ten postintervention semistructured focus groups (mean duration $=53.11, S D=9.98 \mathrm{~min}$ ) were conducted with 6 participants from each intervention school (pupils $N=60$ ). A boy and girl from each tertile of attendance within each school were purposively sampled to elicit a range of views about aspects that they did/did not enjoy, relationships with other participants, perceived effects of the intervention, and their views on the TA.

\section{Quantitative Data Analysis}

Pupil ratings of TA autonomy-support and TA perceptions of their teaching self-efficacy and autonomy-support were analyzed descriptively and plotted graphically. Betweenarms differences in the motivation and need satisfaction 
variables at the end of the intervention and at follow-up were estimated using multivariable linear regression. Initially, unadjusted models were estimated, and then models were adjusted for baseline outcome variable score, BMI, and deprivation. Both unadjusted and adjusted models are presented to facilitate the comparison of our results with results from other trials that are different but comparable, especially where different covariates have been included; this practice is in line with recent recommendations (de Boer, Waterlander, Kuijper, Steenhuis, \& Twisk, 2015). As described by Peters, Richards, Bankhead, Ades, and Sterne (2003), robust standard errors were estimated to account for the clustering of pupils within schools. Previous analysis suggested that the potential effect of the intervention on physical activity differed among boys and girls (Jago et al., 2014). Specifically, supplementary regression analysis suggested that the effect of the intervention on moderate-to-vigorous physical activity on weekdays $(b=-5.1,95 \%$ CI $[-14.0,3.7])$ and in the after-school period $(b=-3.4,95 \%$ CI $[-6.8,-0.42])$ might be modified by gender (coded as boys $=0$ and girls = 1). The Trial Management Group, supported by the Independent Trial Steering Committee, decided that, notwithstanding the exploratory nature of these subgroup analyses, there was reasonable evidence to suggest that the intervention may be differentially effective in boys and girls. On this basis, we sought to explore whether the psychosocial variables also showed any quantitative evidence of differing between boys and girls and probed the qualitative data with participant gender in mind. The study was a feasibility trial; therefore, we examined point estimates and $95 \%$ confidence intervals, and probability values are not presented (Leon, Davis, \& Kraemer, 2011). Data analysis was performed in Stata Version 12 (College Station, TX).

\section{Qualitative Data Analysis}

Interviews and focus groups were recorded, and the audio files were transcribed verbatim. The qualitative data were analyzed using a thematic analysis approach grounded within a realist perspective in which we attempted to capture the participants' experiences and meaning of their experiences within the intervention (Braun \& Clarke, 2006). A predetermined coding frame was developed that pertained to the intervention logistics and practicalities but also fidelity to SDT and perceived effects of the intervention on motivation constructs. Pupil and TA data were initially analyzed separately to identify units of text that spoke to themes within the coding frame (i.e., deductive coding). During this process, relevant codes that inductively arose from the data were also recorded so as to capture the breadth of participants' experiences and views. Frameworks for pupils and TAs, in which codes were organized into higher order themes, were then compared with capture agreement and diversity within themes between the two groups. Triangulation was undertaken between the researchers in which codes and themes identified by one analyst were reviewed by two other analysts. NVivo (Version 10, QSR, Southport, UK) was used to store and manage the data. Six themes related to fidelity to and impact on the SDT-based constructs were identified. These were labeled (a) Motivation: Perceptions of the fun and value of being active, (b) Perceptions of competence, (c) Perceptions of autonomy, (d) Perceptions of relatedness, (e) Children's reflections on the teaching assistants' style, and (f) Teaching assistant views on delivery (which contained the subthemes Drifting from SDT-based motivational strategies \& Challenges to autonomy-supportive delivery).

\section{Results}

\section{Participants}

In total, 539 children (mean age $=10.04, S D=0.57$ ) from 20 primary schools were allocated (at school level) to either intervention or control arms (10 schools in each arm). For the purposes of this study, the quantitative outcomes are reported for 222 boys (intervention $n$ $=109$, control $n=113$ ) and 268 girls (intervention $n=$ 146 , control $n=122$ ) who provided complete data at all three measurement time points (i.e., $N=490$; $90.9 \%$ of randomized participants). Independent samples $t$ tests indicated that included participants were not different from excluded participants on motivation, need satisfaction, deprivation, or BMI. BMI $z$ scores (boys' $M=0.69$, $S D=1.17$; girls' $M=0.50, S D=1.19$ ) were similar to those reported for children at the end of UK primary school (Jago, Fox, Page, Brockman, \& Thompson, 2010).

\section{Preliminary Quantitative and Qualitative Evidence for the Effect of the Intervention on SDT-Based Constructs}

Physical Activity Motivation. Among boys (Table 1), at Time 1 (i.e., the end of the intervention), intrinsic motivation did not differ between groups $(b=-0.03$, $95 \%$ CI $[-0.22,0.16])$. Identified motivation showed a trend toward a small difference in favor of the intervention group at Time $1(b=0.16,95 \%$ CI $[-0.09,0.41)$ and at Time 2 (follow-up) ( $b=0.18,95 \%$ CI [0.03, 0.34]). Introjected motivation did not differ between groups at Time 1 but showed an increase in the intervention versus control group at Time $2(b=0.35,95 \%$ CI $[0.08,0.62])$. External motivation was higher among intervention participants at Time $1(b=0.26,95 \%$ CI $[0.05,0.47])$, and there was a trend for a similar difference at Time 2. Among girls (Table 2), intrinsic ( $b=-0.34,95 \%$ CI $[-0.53,-0.15])$ and identified $(b=-0.34,95 \%$ CI $[-0.48$, $-0.20])$ motivation was lower in the intervention versus control group at Time 1 but was not different at Time 2 . Introjected and external motivations types did not differ between trial arms at either time point.

The qualitative theme Perceptions of the fun and value of being active showed that some boys and girls felt that Action 3:30 had helped them identify some personal reasons for being active (e.g., improving their health 


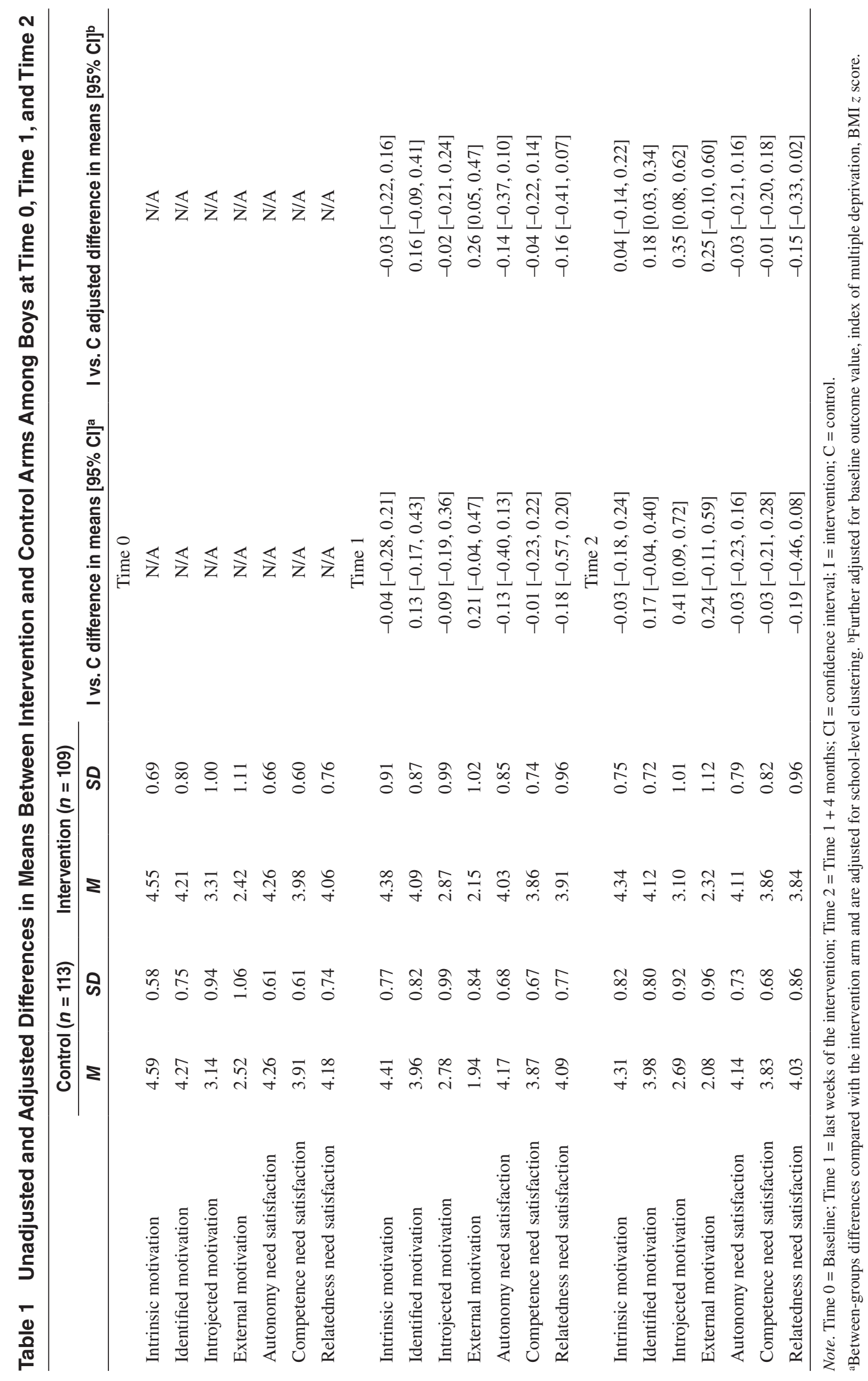




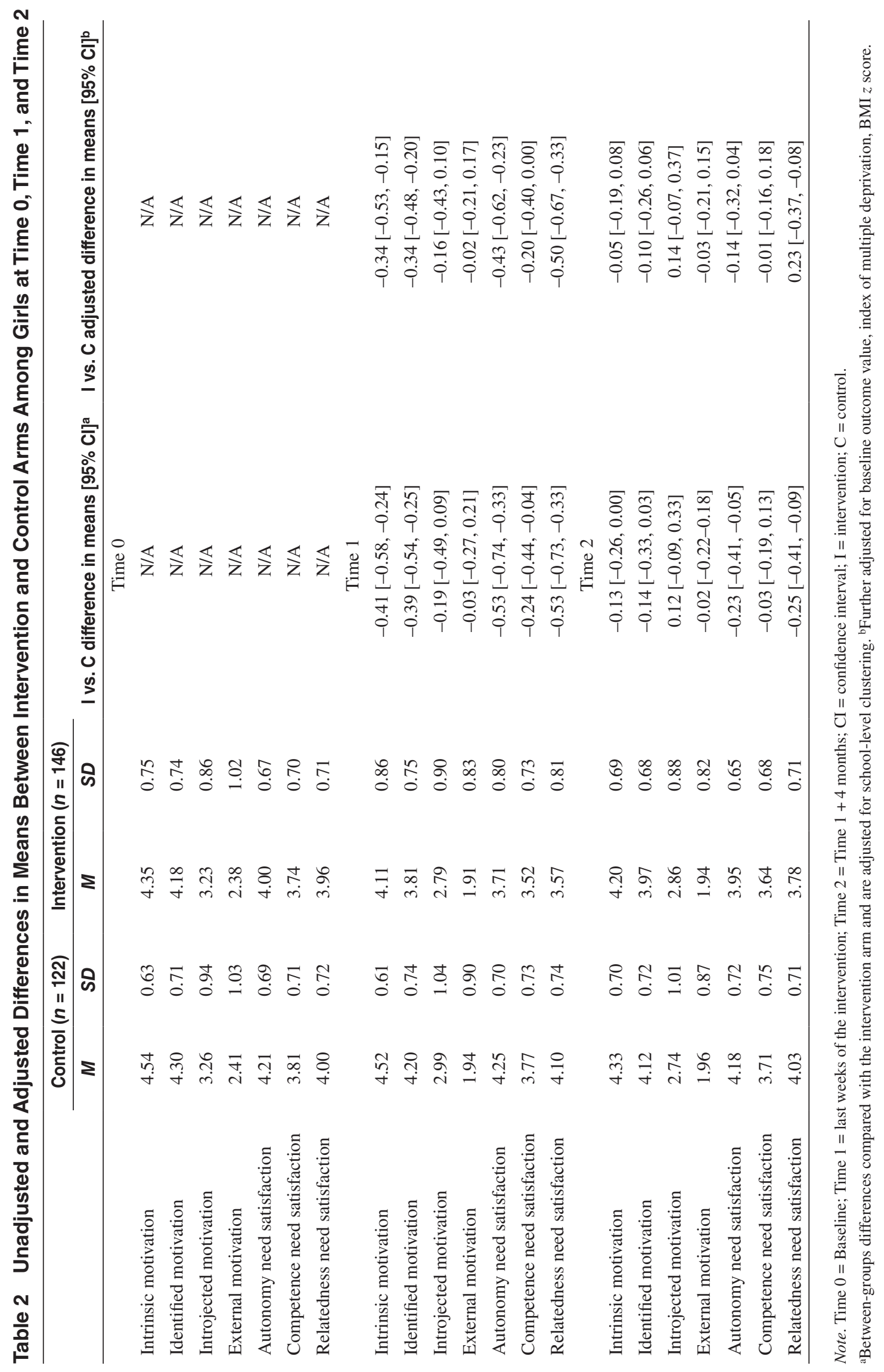


and skills, reducing screen time, playing outdoors, and preparing for secondary school) and that physical activity could be fun. In line with the quantitative findings among boys, some (corroborated by TAs) identified that their motivation had become more self-determined:

Before Action 330 was here my mum would say "You need to go outside," but now before she would say it, I would say "mum can I go outside now and play some games?" I feel like I'm more healthier than I was before... Ifeel like I've done more active things than I was doing before so like, [I've] made myself active but with the help of Action 330. (School 2, Year 5 male)

As a group, the girls held mixed views; some reported that the intervention had increased their intrinsic motivation:

You realise that you're going to have fun whilst being active instead of just like going and running and then getting tired. (School 8, Year 5 female)

However, others' views were more aligned with the quantitative findings among girls that their enjoyment of certain sports had decreased:

Participant: I'm not very good at it [football] and I've been hit in the face about eight times with the ball.

Interviewer: Do you think this [Action 3:30] made you get any better at football or do you like it less now?

Participant: I like it much less now. (School 4, Year 5 female)

Physical Activity Psychological Need Satisfaction. Boys' autonomy need satisfaction did not differ between groups at Time 1 and Time 2 (Table 1). Among girls (Table 2), autonomy was lower in the intervention versus control group at Time $1(b=-0.43,95 \%$ CI $[-0.62$, $-0.23]$ ) but was not different at Time 2. Qualitatively, in the Perceptions of autonomy theme, participants reported experiencing autonomy within the Action 3:30 sessions. Boys felt that this went further than other sports or their PE classes:

Because other clubs I've done, sporting clubs like football, tennis, they just say "right, we're doing this, full stop". But in Action 3:30, we had choices and options, and we could change the games [... ] (School 9, Year 6 male)

This was influenced strongly by the child-led sessions (in which participants guided the session's activities, which were structured with the TAs' help), and child input was also welcomed and valued by the TAs:

I think the way it gets everyone involved worked really well and the fact that the children can be involved in planning the sessions because some of them are pupil-led, so they get involved and they can say what they want to do and they thought that it was their club. (TA, School 19, female)

Generally, although not exclusively, the views of boys related to positive experiences of having choice and input. Although some girls reported experiencing choice ("we got to choose what groups we want to be in and what we want to do as well," School 8, Year 5 female), the majority of references girls made to autonomy reflected negative experiences:

Sometimes they didn't really give us a choice to change the game that we were playing so I thought maybe they could have let us say our ideas and then maybe explain a better way to do it. (School 6, Year 6 female)

Competence need satisfaction was unchanged at Time 1 and 2 among boys (Table 1). Girls showed a trend toward having lower competence in the intervention versus control group at Time $1(b=-0.20,95 \% \mathrm{CI}$ $[-0.40,0.00])$ but not at Time 2 (Table 2 ). The qualitative Perceptions of competence findings were partially consistent with the quantitative findings. Although there was no quantitative evidence of differences in boys' competence, improved sports/activity competence was common to both boys' and girls' narratives:

It's changed what I like to do now because it's made me want to [ . . .] do to everything that I didn't think I could ever do. And it made me more fit [ . . ] to do what I want. (School 8, Year 6 male)

Several girls reported that their increased competence had influenced their broader identity as an active person and improved their self-esteem:

It's made me feel more sporty and active because I used to be a slow runner, but now I'm really fast. And I'm really proud of myself because if we have like, races I could win them now ... so I think it's really helped me. (School 19, Year 5 female)

Other girls, however, viewed some activities as unchallenging and better suited to younger children, which may have not provided enough opportunity to increase their competence:

Like that hop scotch game. It was just like babyish. (School 10, Year 5 female)

TAs thought that participants' sports skills and attitude toward approaching new tasks improve within and beyond Action 3:30:

. . . they improved their skills . . . being able to encourage teammates, good teamwork, their personal confidence and their competence, their actual ability to do things. [...] And I think they discovered quite a lot about themselves and what they are actually good at. (TA, School 9, female) 
Relatedness need satisfaction among boys was not different between the intervention and control arm at Time 1 or Time 2 (Table 1) but was lower among girls in the intervention versus control group at Time $1(b=$ $-0.50,95 \%$ CI $[-0.67,-0.33])$. This difference persisted but was smaller at Time 2 (Table 2). Qualitatively and in contrast to the quantitative findings, the majority of participants expressed a development of new friendships and that having or making friends in Action 3:30 was important and central to their enjoyment:

I like Action 3.30 because we bonded with people we wouldn't usually bond with. (School 4, Year 6 female)

One boy described how relatedness developed between boys and girls because of the mixed-gender structure of Action 3:30, which was different and preferred to usual single-sex sports:

I like Action 3:30 because normally when I join a club, it's like... there are lots of girls doing it and it's obviously girly sport, [ . . ] Or when I join a boys' club ... it's only boys'stuff, [ . . . ] but in Action 3:30 it was girls' sports and boys' sports mixed together, so all of us could come together to do it. We both had fair teams. (School 19, Year 6 male)

In contrast, some participants felt that there was insufficient interfriendship group mixing: "Some people stuck with the same people" (School 9, Year 5 male). While participants did not refer to their connection with the TAs, the TAs reported forming strong relationship with the participants, particularly those they did not already know:

... seeing them after school, when I'm passing them in the corridor, I have more of a rapport with them. (TA, School 9, female)

\section{TA's Fidelity to and Experiences of the SDT Components of the Intervention}

TA-Reported Provision of Autonomy-Support, Structure, and Involvement. Structure was rated higher than autonomy-support and involvement at all assessments (Figure 1). While the provision of structure showed an increasing trend over the course of the intervention, involvement and autonomy-support declined similarly from PEV1 to PEV3 and increased to initial levels at PEV4.

TA Self-Efficacy to Teach Physical Activity. TAs' self-efficacy when faced with institutional $(M=62.03$, $S D=3.83)$ and space-related challenges $(M=65.90$, $S D=4.61)$ was lower than when faced with time $(M=$ $70.45, S D=1.10)$ and student-based $(M=73.38, S D$ $=1.57$ ) challenges (Figure 2 ). Over the course of the intervention, institutional self-efficacy increased but remained the lowest rated form. Space-related efficacy fluctuated but increased over the course of the intervention. Time- and student-based efficacy were scored similarly and were relatively stable for the intervention period.

\section{TAs' Views of Delivering Action 3:30.}

TAs were accepting of the autonomy-supportive motivational approach promoted in the SDT-based training and intervention manual and they believed that they used elements of this in their session leadership:

Oh, I like it. It's very close to what we do, you know, in the classroom. I like the fact that you're encouraging each child at the level that they're at and the kind of careful wording. (TA, School 8, female)

Some TAs reported purposefully using the motivational techniques:

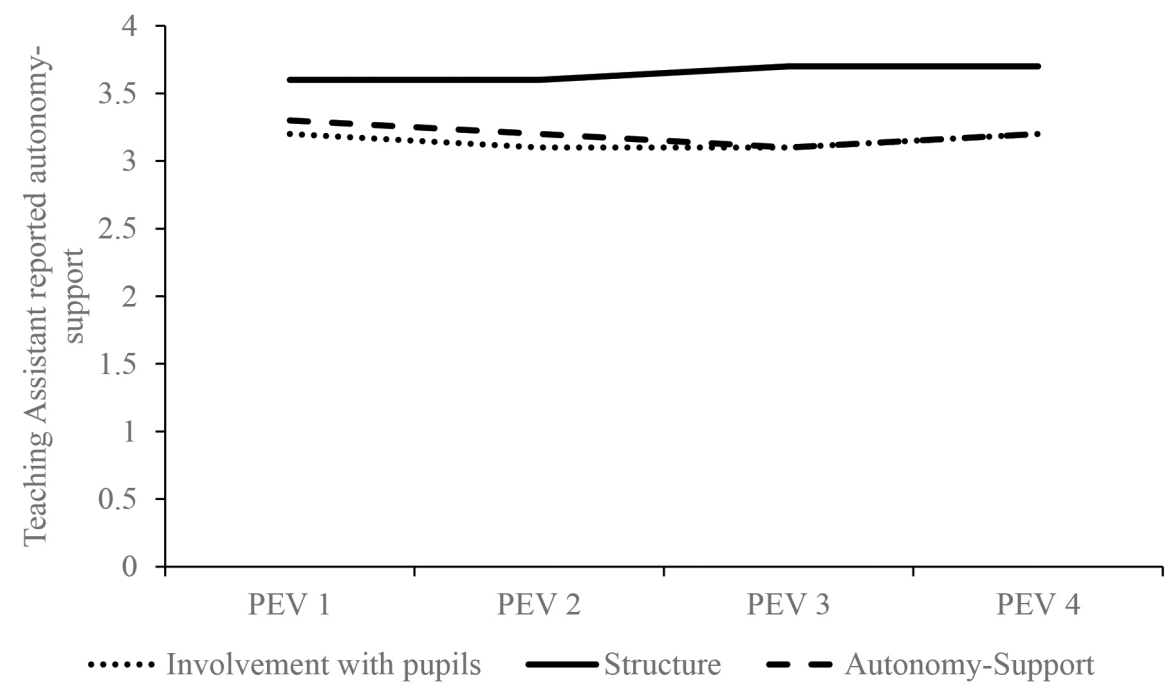

Figure 1 - Teaching assistant-reported provision of autonomy support during the Action 3:30 intervention. PEV = Process Evaluation Visit. 


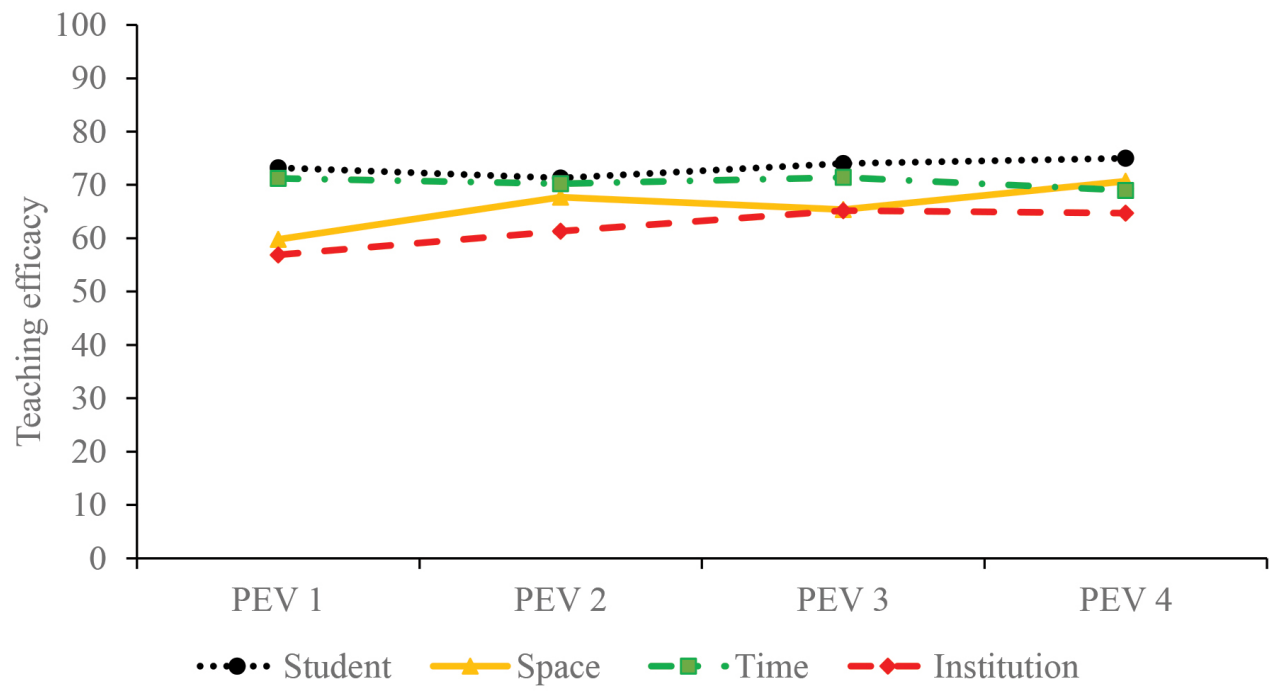

Figure 2 - Teaching assistant physical activity teaching self-efficacy during the Action 3:30 intervention. PEV = Process Evaluation Visit.

We didn't say, "You have to do this. You have to do this" but just try to get them involved and we just made it fun and we asked for their opinion, "What games do you like?" That made them even more motivated. (TA, School 19, female)

In contrast, others reported only using the strategies with children who did not seem motivated or felt that they did not need to use the techniques because they perceived the children to be sufficiently motivated and easy to manage:

We did [use motivation techniques], but to be honest, we didn't need them a lot. I felt that they were all keen to come. (TA, School 2, female)

Drifting From SDT-Based Motivational Strategies. Some TAs reported using motivational techniques that were not promoted in the training that focused on providing rewards. One strategy involved voting for a "club person," which acknowledged/appreciated their contribution to the group; the other strategy focused on providing tangible performance-based rewards:

We have star of the day award, so we give out certificates and rewards for the person who... might have been the best listener, best behaved, best catcher, best thrower, so something like that might be more of an incentive to keep them involved. (TA, School 10 , male)

Other TAs considered using rewards to motivate their children but did not:

We thought about [it] you know? Perhaps giving them rewards and things like that, but they shouldn't really be ... we didn't think it was right to go down that road. They should be coming because they signed up to come. (TA, School 12, female)

Challenges to Autonomy-Supportive Delivery. TAs recognized children's preference for and enjoyment of having autonomy:

The children struggled quite a lot sometimes with when we rigidly stuck to the activities with not having a choice themselves. They wanted it to be their club. And they felt that, you know, if they were going to take ownership of it . . . why should they do an activity they didn't want to do. (TA, School 8, female)

However, although structure was reported as high in the quantitative data, qualitatively TAs revealed that granting children more autonomy, especially in the "child-led" sessions, required greater planning to provide necessary structure:

Possibly we should have put in a bit more structure there [child-led sessions]. Maybe we should have perhaps thought about those a bit more, rather than just say, "Aw, chalk that. Let's just get on with it." (TA, School 6, female)

In addition, dealing with disruptive behavior prevented the TAs from supporting all children's needs:

We had to put in a lot of effort to control the behavior. When you do that you tend to focus on the children that do not behave and the others feel a bit neglected.

(TA, School 19, female)

Others reported using consistent strategies for managing disruptive behavior including using the school behavior policy and the "Club Pledge" (where TAs asked children to help develop the club rules at the start of the intervention): 
Yes and having the pledge [. . . ] we had to make up rules and they had to sign it. They agreed what things they would feel that made the club work. (TA, School 2, female)

\section{Pupil's Perceptions of TAs' Delivery Style}

Pupil-Rated TA Autonomy-Support. This was rated as moderate-to-high at PEV1 $(M=4.94, S D=1.50)$, declined linearly to PEV3 $(M=4.07, S D=1.40)$, and returned to near initial levels by PEV4 $(M=4.70, S D=$ 1.40). Qualitatively, participants commonly differentiated TAs being "strict" versus "kind" or "relaxed" and open versus resistant to their input, and they preferred a balance between these approaches:

If you just had like relaxed people then you wouldn't really do anything, but if you just had strict people then it wouldn't be fun. So together it's like fun, but not like silly and you do stuff. (School 10, Year 5 female)

Participants did not like being moved on from an activity that they were enjoying to another. Some TAs overcame this by using the session plans flexibly:

If they really enjoyed it, we'd carry on a bit longer. If not, we'd move on. We probably didn't do it [stick to the manual] . . religiously because we were trying to make it fun for them, we tried to work with them. (TA, School 2, female)

\section{Discussion}

By combining quantitative and qualitative findings, we have presented a rich account of the experiences of the participants and deliverers of the Action 3:30 after-school physical activity intervention with regard to the fidelity to and effectiveness of the intervention's theoretical underpinning. The preliminary quantitative evidence gathered in this feasibility trial suggested that all motivation types among boys tended to decrease over time in both control and intervention groups. There was some evidence that the intervention buffered the reductions in identified and external motivation at the end of the intervention. The findings are in contrast to a shorter intervention in which PE teacher style was manipulated that increased relative autonomous motivation for PE (Chatzisarantis \& Hagger, 2009). At the 4-month (Time 2) follow-up, boys' intrinsic motivation did not differ between groups whereas identified, introjected, and external (trend) motivation for physical activity was higher among intervention versus control group participants. It seems contradictory that the intervention may have prompted greater identified motivation (Time 1 and 2) alongside introjected (Time 2) and external motivation (Time 1 and 2) among boys. Identified and introjected regulation are conceptually adjacent on the self-determination continuum (Deci \& Ryan, 2000) and positively correlated in the context of children's physical activity when using the measure employed (Sebire et al., 2013). The qualitative results suggested that the intervention helped boys to identify the fun and their own personal reasons for being active, yet there was little qualitative evidence that they felt externally pressured to be active. A speculative explanation is that although the questionnaires measured motivation toward broad physical activity (rather than being active in Action 3:30) at Time 1, boys in the intervention group may have endorsed items such as "because someone says I should" based on their current experiences of being active under instruction of an Action 3:30 leader. Qualitative research with participants at follow-up (Time 2) would have allowed us to explore the nature of introjection outside of the intervention context. Researchers could consider embedding multiple qualitative phases in their process evaluation design, especially where hypothesized mediators (e.g., motivation) are dynamic in nature. Future work could also seek to develop a better understanding of how to differentiate motivational types in young people and operationalize these more clearly in questionnaires.

There was no quantitative evidence of a potential intervention effect on boys' need satisfaction. This was contradicted by the qualitative results in which boys commonly reported that the intervention had increased their perceptions of competence, ownership, and choice and helped develop new friendships. In contrast to research that has found associations between young people's contextual motivation (e.g., toward PE) and leisure time activity (Hagger, Chatzisarantis, Culverhouse, \& Biddle, 2003) it appears that perceptions within Action 3:30 were not strong enough on average to transfer to an effect on broader physical activity need satisfaction.

There was some quantitative evidence that the intervention had a potentially negative effect on girls' intrinsic and identified motivation at Time 1 and on girls' psychological need satisfaction at the end of the intervention. The effects on autonomy and relatedness persisted at follow-up. These results were the opposite of what was expected; however, we have previously reported that there was no evidence of an effect of the intervention on girls' physical activity (Jago et al., 2014) and have proposed improvements to the intervention to better accommodate girls' preferences (Jago et al., 2015). Both findings are illuminated by the present qualitative results, which show that while some girls reported empowerment, increased competence, and new friendships, others reported a lack of choice and inconsistent autonomy-support from some TAs. These findings suggest that the intervention could be refined to ensure greater need satisfaction for girls. Examples of such refinements include (a) involving girls and boys equally in decision-making, ensuring that boys or their choices (e.g., often for football) do not dominate sessions; (b) building on pupils' identification that mixedgender teams can be fair and minimize perceptions of boys' sports versus girls'sports; (c) setting activities that can accommodate the initial range of competence levels and the rates of progression among girls and boys; and (d) discussing the physical activity preferences of girls 
and boys with TAs during their training. It is important, however, that these refinements and messages are not presented to or interpreted by TAs as diluting the intervention for girls but rather as making it equally engaging, challenging, and rewarding for boys and girls.

Intervention participants reported that the TAs provided moderate-to-high autonomy-support throughout the program. TA reports were similar, but they reported providing greater structure than either autonomy-support or involvement. Previous work suggests that trained teachers are comfortable using structure-based strategies and may need more training in autonomy-support techniques (Aelterman et al., 2013). In line with this work (Aelterman et al., 2013) TAs reported that they were accepting of the SDT-based training. They described using autonomy-supportive techniques; however, some believed that they only needed to be used to encourage less motivated children, and at two schools a reward system was introduced that was counter to the intervention theory. While TAs reported relatively high efficacy for delivering sessions while facing student-based issues, they viewed negotiation with pupils, the need for extra planning and preparation, and managing disruptive behavior as specific challenges to autonomy-supportive delivery. These findings are consistent with some of the antecedents to the use of controlling teaching practices among PE teachers identified in previous work (Taylor, Ntoumanis, \& Smith, 2009), including time constraints, contemporary professional expectations for formal rather than informal (e.g., having fun and social interactions) teacher-pupil relationships, and teachers' perceptions of the pupils (including their motivation and poor discipline). TAs' efficacy to deliver the sessions was lowest when facing institutional and space-related challenges, which is similar to previous research among novice PE teachers (Martin, McCaughtry, Hodges Kulinna, \& Cothran, 2009) with whom some of the TAs could be compared. Together, these findings highlight the importance of future interventions like Action 3:30 garnering institutional support and collaboration and addressing the potential reasons why, or circumstances under which, intervention deliverers might use or revert to controlling teaching strategies and practical ways to manage this.

We have previously reported the practicalities and feasibility of delivering the Action 3:30 intervention including successful recruitment of schools, TAs, and pupils and a high rate of delivery of the intended sessions and data provision (Jago et al., 2015). Based on the present findings, delivering the SDT-based components of the intervention also appears to be feasible although in a future trial the following refinements would address some of the challenges to fidelity to the underpinning theory: (a) emphasizing the use of autonomy-supportive techniques with all students, regardless of their motivation; (b) providing guidance on how to support psychological needs effectively among girls; (c) adapting the TA training to focus on how to balance structure with autonomy-support and involvement; (d) annotating session plans with clearer indications of need-supportive activities, phrases, or actions; and (e) developing a motivational strategy that meets TAs' desire to use rewards while also supporting children's self-regulation.

\section{Strengths and Limitations}

To our knowledge, this study represents the first mixedmethods theory-based process evaluation of an SDTinformed primary-school-based PA intervention. The quantitative and qualitative results, documenting the perspectives of multiple informants, have provided an in-depth exploration of the processes of intervention delivery by TAs and receipt as experienced by children. As a result, we have identified successful components of the intervention alongside challenges and pragmatic improvements to make before proceeding to further evaluation of the trial. While the between-arms quantitative analysis provides evidence of promise, the nature of the feasibility trial means that these findings should not be interpreted as evidence of effectiveness, which would need to be identified within a definitive trial. In addition, conducting further qualitative research with intervention participants at follow-up would have added to our interpretation of the motivational dynamics once the intervention had ended. We chose to conduct the process evaluation interviews blind to the quantitative outcomes to avoid unduly influencing the focus group or interview discussions, but this meant that the qualitative interviews and focus groups were not able to directly probe some of the interesting quantitative findings (e.g., possibly reduced identified motivation or relatedness among girls). However, following quantitative analysis we thoroughly reviewed the qualitative data for evidence to enhance our understanding of these findings. We did not conduct objective assessments of leaders' use of theory-based strategies (i.e., TA delivery style), which could enhance our understanding of fidelity and could be achieved using observation systems (Haerens et al., 2013). Further, we did not formally rate the provision of SDT principles in our training of the TAs, nor did we interview the Local Authority employee who provided the training, which would also be informative about this important step in the intervention. A related limitation is that the intervention model, at this stage of development, relied on one Local Authority employee's providing training to the group of TAs. In a larger trial or rollout of this intervention, it may be necessary to use multiple Local Authority trainers, which could challenge intervention fidelity; however, the current study cannot shed light on this issue. Finally, we did not measure TA autonomy-support or self-efficacy to deliver PA sessions before the training. Unlike studies that have trained PE teachers to adopt an autonomy-supportive style in their classes (Tessier et al., 2010), within Action 3:30, deliverers were trained to deliver new content, in a new setting and to new pupils. It is difficult therefore to identify pretraining measures that would have enabled us to estimate its effectiveness. 


\section{Conclusion}

The theory-based components of the Action 3:30 intervention can, on the whole, be delivered as intended and may hold some promise to positively influence boys' physical activity motivation. Refinements to the intervention are needed to enhance theoretical fidelity, to enhance the intervention effect for boys, and to positively impact girls' motivation and need satisfaction. The study demonstrates the value that detailed, mixed-methods process evaluation can add to understanding theory-based physical activity interventions.

\section{Acknowledgments}

This study was funded by the National Prevention Research Initiative, which is supported by Alzheimer's Research Trust; Alzheimer's Society; Biotechnology and Biological Sciences Research Council; British Heart Foundation; Cancer Research UK; Chief Scientist Office, Scottish Government Health Directorate; Department of Health; Diabetes UK; Economic and Social Research Council; Health and Social Care Research and Development Division of the Public Health Agency (HSC R\&D Division); Medical Research Council; The Stroke Association; Wellcome Trust; Welsh Assembly Government; and World Cancer Research Fund (MRC reference-MR/J000191/1).

\section{References}

Aelterman, N., Vansteenkiste, M., Van den Berghe, L., De Meyer, J., \& Haerens, L. (2014). Fostering a needsupportive teaching style: Intervention effects on physical education teachers' beliefs and teaching behaviors. Journal of Sport \& Exercise Psychology, 36(6), 595-609. PubMed doi:10.1123/jsep.2013-0229

Aelterman, N., Vansteenkiste, M., Van Keer, H., De Meyer, J., Van den Berghe, L., \& Haerens, L. (2013). Development and evaluation of a training on need-supportive teaching in physical education: Qualitative and quantitative findings. Teaching and Teacher Education, 29, 64-75. doi:10.1016/j.tate.2012.09.001

Amorose, A.J., \& Anderson-Butcher, D. (2007). Autonomysupportive coaching and self-determined motivation in high school and college athletes: A test of self-determination theory. Psychology of Sport and Exercise, 8(5), 654670. Retrieved from <Go to ISI >://000249631500006

Bartholomew, K.J., Ntoumanis, N., \& Thogersen-Ntoumani, C. (2009). A review of controlling motivational strategies from a self-determination theory perspective: Implications for sports coaches. International Review of Sport and Exercise Psychology, 2(2), 215-233. doi:10.1080/17509840903235330

Belmont, M., Skinner, E., Wellborn, J., \& Connell, J. (1988). Teacher as social context: A measure of student perceptions of teacher provision of involvement, structure, and autonomy support (Tech. rep. no. 102). Rochester, NY: University of Rochester.
Braun, V., \& Clarke, V. (2006). Using thematic analysis in psychology. Qualitative Research in Psychology, 3, 77-101. doi:10.1191/1478088706qp063oa

Chatzisarantis, N.L., \& Hagger, M.S. (2009). Effects of an intervention based on self-determination theory on self-reported leisure-time physical activity participation. Psychology \& Health, 24(1), 29-48. PubMed doi:10.1080/08870440701809533

Cole, T.J., Freeman, J.V., \& Preece, M.A. (1995). Body-mass index reference curves for the UK, 1990. Archives of Disease in Childhood, 73(1), 25-29. PubMed doi:10.1136/ adc.73.1.25

Contento, I.R., Koch, P.A., Lee, H., \& Calabrese-Barton, A. (2010). Adolescents demonstrate improvement in obesity risk behaviors after completion of Choice, Control \& Change, a curriculum addressing personal agency and autonomous motivation. Journal of the American Dietetic Association, 110(12), 1830-1839. PubMed doi:10.1016/j. jada.2010.09.015

de Boer, M.R., Waterlander, W.E., Kuijper, L.D., Steenhuis, I.H., \& Twisk, J.W. (2015). Testing for baseline differences in randomized controlled trials: An unhealthy research behavior that is hard to eradicate. The International Journal of Behavioral Nutrition and Physical Activity, 12, 4. PubMed doi:10.1186/s12966-015-0162-z

Deci, E.L., \& Ryan, R.M. (2000). The "what" and "why" of goal pursuits: Human needs and the self-determination of behavior. Psychological Inquiry, 11, 227-268. doi:10.1207/S15327965PLI1104_01

Dishman, R.K., McIver, K.L., Dowda, M., Saunders, R.P., \& Pate, R.R. (2015). Motivation and behavioral regulation of physical activity in middle-school students. Medicine and Science in Sports and Exercise. PubMed doi:10.1249/ MSS.0000000000000616

Fortier, M.S., Duda, J.L., Guerin, E., \& Teixeira, P.J. (2012). Promoting physical activity: Development and testing of self-determination theory-based interventions. The International Journal of Behavioral Nutrition and Physical Activity, 9, 20. PubMed doi:10.1186/1479-5868-9-20

Glanz, K., \& Bishop, D.B. (2010). The role of behavioral science theory in development and implementation of public health interventions. Annual Review of Public Health, 31, 399-418. PubMed doi:10.1146/annurev. publhealth.012809.103604

Gray, H.L., Contento, I.R., \& Koch, P.A. (2015). Linking implementation process to intervention outcomes in a middle school obesity prevention curriculum, 'Choice, Control and Change.' Health Education Research, 30(2), 248-261. PubMed doi:10.1093/her/cyv005

Haerens, L., Aelterman, N., Van den Berghe, L., De Meyer, J., Soenens, B., \& Vansteenkiste, M. (2013). Observing physical education teachers' need-supportive interactions in classroom settings. Journal of Sport \& Exercise Psychology, 35(1), 3-17. Retrieved from http://www.ncbi.nlm.nih. gov/pubmed/23404876. PubMed doi:10.1123/jsep.35.1.3

Hagger, M.S., Chatzisarantis, N.L.D., Culverhouse, T., \& Biddle, S.J.H. (2003). The processes by which perceived autonomy support in physical education promotes leisuretime physical activity intentions and behavior: A trans-con- 
textual model. Journal of Educational Psychology, 95(4), 784-795. Retrieved from $<$ Go to ISI $>$ ://000186640500010

Hanson, M.D., \& Chen, E. (2007). Socioeconomic status and health behaviors in adolescence: A review of the literature. Journal of Behavioral Medicine, 30, 263-285. PubMed doi:10.1007/s10865-007-9098-3

Jago, R., Edwards, M.J., Cooper, A.R., Fox, K.R., Powell, J., Sebire, S.J., . . Montgomery, A.A. (2013). Action 3:30: protocol for a randomized feasibility trial of a teaching assistant led extracurricular physical activity intervention. Trials, 14, 122. doi:10.1186/1745-6215-14-122

Jago, R., Fox, K.R., Page, A.S., Brockman, R., \& Thompson, J.L. (2010). Parent and child physical activity and sedentary time: Do active parents foster active children? BMC Public Health, 10. PubMed doi:10.1186/ 1471-2458-10-194

Jago, R., Sebire, S.J., Davies, B., Wood, L., Banfield, K., Edwards, M.J., . . Fox, K.R. (2015). Increasing children's physical activity through a teaching-assistant led extracurricular intervention: process evaluation of the action 3:30 randomised feasibility trial. BMC Public Health, 15, 156. doi:10.1186/s12889-015-1501-3

Jago, R., Sebire, S.J., Davies, B., Wood, L., Edwards, M.J., Banfield, K., . . Montgomery, A.A. (2014). Randomised feasibility trial of a teaching assistant led extracurricular physical activity intervention for 9 to 11 year olds: Action 3:30. The International Journal of Behavioral Nutrition and Physical Activity, 11, 114. doi:10.1186/s12966-0140114-z

Janssen, I., \& LeBlanc, A.G. (2010). Systematic review of the health benefits of physical activity and fitness in schoolaged children and youth. The International Journal of Behavioral Nutrition and Physical Activity, 7, 40. PubMed doi:10.1186/1479-5868-7-40

Kok, G. (2014). A practical guide to effective behavior change: How to apply theory- and evidence -based behavior change methods in an intervention. The European Health Psychologist, 16(5), 156-170.

Leon, A.C., Davis, L.L., \& Kraemer, H.C. (2011). The role and interpretation of pilot studies in clinical research. Journal of Psychiatric Research, 45(5), 626-629. PubMed doi:10.1016/j.jpsychires.2010.10.008

Lonsdale, C., Rosenkranz, R.R., Sanders, T., Peralta, L.R., Bennie, A., Jackson, B., . . . Lubans, D.R. (2013). A cluster randomized controlled trial of strategies to increase adolescents' physical activity and motivation in physical education: Results of the Motivating Active Learning in Physical Education (MALP) trial. Preventive Medicine, 57(5), 696-702. PubMed doi:10.1016/j.ypmed.2013.09.003

Mageau, G.A., \& Vallerand, R.J. (2003). The coach-athlete relationship: A motivational model. Journal of Sports Sciences, 21(11), 883-904. Retrieved from < Go to ISI>://000186010900002

Martin, J.J., \& Kulinna, P.H. (2003). The development of a physical education teachers' physical activity self-efficacy instrument. Journal of Teaching in Physical Education, 22, 219-232. doi:10.1123/jtpe.22.2.219

Martin, J.J., McCaughtry, N., Hodges Kulinna, P., \& Cothran, D. (2009). The impact of a social cognitive theory-based intervention on physical education teacher self-efficacy. Professional Development in Education, 35, 511-529. doi:10.1080/19415250902781814

Moore, G., Audrey, S., Barker, M., Bond, L., Bonell, C., Hardeman, W., \& Baird, J. (2014). Process evaluation of complex interventions. UK Medical Research Council (MRC) guidance. Retrieved from https://www.mrc.ac.uk/documents/ pdf/mrc-phsrn-process-evaluation-guidance-final/.

Mouratidis, A., Lens, W., \& Vansteenkiste, M. (2010). How you provide corrective feedback makes a difference: The motivating role of communicating in an autonomy-supporting way. Journal of Sport \& Exercise Psychology, 32(5), 619-637. Retrieved from http://www.ncbi.nlm.nih.gov/ pubmed/20980707. PubMed doi:10.1123/jsep.32.5.619

Mouratidis, A., Vansteenkiste, M., Lens, W., \& Sideridis, G. (2008). The motivating role of positive feedback in sport and physical education: Evidence for a motivational model. Journal of Sport \& Exercise Psychology, 30, 240-268. Retrieved from < Go to ISI $>$ ://000255109700007

Mullan, E., Markland, D., \& Ingledew, D.K. (1997). A graded conceptualisation of self-determination in the regulation of exercise behaviour: Development of a measure using confirmatory factor analytic procedures. Personality and Individual Differences, 23, 745-752. doi:10.1016/S01918869(97)00107-4

Nader, P.R., Bradley, R.H., Houts, R.M., McRitchie, S.L., \& O'Brien, M. (2008). Moderate-to-vigorous physical activity from ages 9 to 15 years. Journal of the American Medical Association, 300(3), 295-305. PubMed doi:10.1001/ jama.300.3.295

Ng, J.Y., Ntoumanis, N., Thogersen-Ntoumani, C., Deci, E.L., Ryan, R.M., Duda, J.L., \& Williams, G.C. (2012). Self-determination theory applied to health contexts: A meta-analysis. Perspectives on Psychological Science, 7(4), 325-340. PubMed doi:10.1177/1745691612447309

Ntoumanis, N., \& Standage, M. (2009). Motivation in physical education classes: A self-determination theory perspective. Theory and Research in Education, 7, 194-202. doi:10.1177/1477878509104324

Owen, K.B., Smith, J., Lubans, D.R., Ng, J.Y., \& Lonsdale, C. (2014). Self-determined motivation and physical activity in children and adolescents: A systematic review and meta-analysis. Preventive Medicine, 67, 270-279. PubMed doi:10.1016/j.ypmed.2014.07.033

Pardo, B.M., Bengoechea, E.G., Julian Clemente, J.A., \& Lanaspa, E.G. (2014). Empowering adolescents to be physically active: Three-year results of the Sigue la Huella intervention. Preventive Medicine, 66, 6-11. PubMed doi:10.1016/j.ypmed.2014.04.023

Peters, T.J., Richards, S.H., Bankhead, C.R., Ades, A.E., \& Sterne, J.A. (2003). Comparison of methods for analysing cluster randomized trials: An example involving a factorial design. International Journal of Epidemiology, 32(5), 840-846. Retrieved from http://www.ncbi.nlm.nih. gov/pubmed/14559762. PubMed doi:10.1093/ije/dyg228

Reeve, J., Jang, H., Carrell, D., Jeon, S., \& Barch, J. (2004). Enhancing students' engagement by increasing teachers' autonomy support. Motivation and Emotion, 28, 147-169. doi:10.1023/B:MOEM.0000032312.95499.6f 
Robbins, L.B., Pfeiffer, K.A., Vermeesch, A., Resnicow, K., You, Z., An, L., \& Wesolek, S.M. (2013). "Girls on the Move" intervention protocol for increasing physical activity among low-active underserved urban girls: A group randomized trial. BMC Public Health, 13, 474. PubMed doi:10.1186/1471-2458-13-474

Ryan, R.M., Patrick, H., Deci, E.L., \& Williams, G.C. (2008). Facilitating health behavior change and its maintenance: Interventions based on self-determination theory. The European Health Psychologist, 10, 2-5.

Sebire, S.J., Jago, R., Fox, K.R., Edwards, M.J., \& Thompson, J.L. (2013). Testing a self-determination theory model of children's physical activity motivation: A cross-sectional study. The International Journal of Behavioral Nutrition and Physical Activity, 10, 111. PubMed doi:10.1186/14795868-10-111

Standage, M., Duda, J.L., \& Ntoumanis, N. (2006). Students' motivational processes and their relationship to teacher ratings in school physical education: A self-determination theory approach. Research Quarterly for Exercise and Sport, 77(1), 100-110.

Taylor, I.M., Ntoumanis, N., \& Smith, B. (2009). The social context as a determinant of teacher motivational strategies in physical education. Psychology of Sport and Exercise, 10, 235-243. doi:10.1016/j.psychsport.2008.09.002

Teixeira, P.J., Carraca, E.V., Markland, D., Silva, M.N., \& Ryan, R.M. (2012). Exercise, physical activity, and self-deter- mination theory: A systematic review. The International Journal of Behavioral Nutrition and Physical Activity, 9(78). PubMed

Tessier, D., Sarrazin, P., \& Ntoumanis, N. (2010). The effect of an intervention to improve newly qualified teachers' interpersonal style, students motivation and psychological need satisfaction in sport-based physical education. Contemporary Educational Psychology, 35, 242-253. doi:10.1016/j.cedpsych.2010.05.005

Wechsler, H., Devereaux, R.S., Davis, M., \& Collins, J. (2000). Using the school environment to promote physical activity and healthy eating. Preventive Medicine, 31(2), S121S137. doi:10.1006/pmed.2000.0649

Wilson, D.K., Griffin, S., Saunders, R.P., Kitzman-Ulrich, H., Meyers, D.C., \& Mansard, L. (2009). Using process evaluation for program improvement in dose, fidelity and reach: The ACT trial experience. The International Journal of Behavioral Nutrition and Physical Activity, 6, 79. PubMed doi:10.1186/1479-5868-6-79

Wilson, D.K., Van Horn, M.L., Kitzman-Ulrich, H., Saunders, R., Pate, R., Lawman, H.G., . . . Brown, P.V. (2011). Results of the "Active by Choice Today" (ACT) randomized trial for increasing physical activity in low-income and minority adolescents. Health Psychology, 30(4), 463-471. PubMed doi:10.1037/a0023390 